\title{
Parkinson's disease and affective disorder: The temporal relationship
}

\author{
Flemming Mørkeberg Nilsson
}

Department of Psychiatry, Psychiatric Centre Hvidovre, University Hospital of Copenhagen, Copenhagen, Denmark

Email: d239453@dadlnet.dk

Received 27 January 2012; revised 25 February 2012; accepted 11 March 2012

\begin{abstract}
In relationship between the affective disorders and Parkinson's disease (PD) it was found that comorbidity was higher than expected in the majority of the studies. Patients with PD are at increased risk of developing depression and, conversely, recent studies have shown that patients with depressive disorders have increased risk of incident PD. However, the temporal associations between the disorders are not fully elucidated. From this review it could be learned that the temporal aspects strongly suggest that a neurobiological association exists between affective disorder and PD. This is illustrated with hitherto unpublished data. Some of these issues may be investigated in case register studies, e.g. by linkage of registers of somatic and psychiatric illness, and suggestions for future research are given. For GP's, psychiatrists, geriatricians, and neurologists these new findings will lead to a better understanding and better treatment for patients with complicated comorbid conditions. Here timing is important!
\end{abstract}

Keywords: Parkinson's Disease; Affective Disorder; Depression; Mania; Temporal Relations

\section{INTRODUCTION}

Parkinson's disease (PD) is a movement disorder. However, often the diagnosis of PD can be preceded or followed by psychiatric symptoms [1-4]. And non-motor symptoms have been recognised as important in recent papers $[5,6]$.

Several findings suggest that the major affective disorders are brain disorders. With the new imaging techniques, computerised tomography (CT-scan), magnetic resonance imaging (MRI) and functional magnetic resonance imaging (f-MRI) neuropathological studies can be conducted on the living brain [7]. Brain imaging studies indicate that a substantial number of patients with affective disorders present with functional and structural changes in the brain [8]. The changes have been reported to be located in multiple regions of the brain, e.g. the frontal, temporal and occipital cortex, the limbic system, including the thalamus and hypothalamus, and diffusely as hyperintensities in the white matter substance [9]. It can be concluded that structural and/or functional changes have been found in different regions of the brain in patients with affective disorders, but in some regions the results are more controversial than in others. Recently, many extensive reviews have been published, both on the anatomical findings of mood disorders [8,9], and several on functional neuroimaging [10-13]. Transcranial sonography (TCS) has recently shown promising results in the diagnosis and prognosis in PD [14] and is very interesting in PD patients with depression $[15,16]$.

The epidemiological comorbidity between major affective disorders and other psychiatric disorders such as anxiety disorders (panic attack, panic disorder, social phobias, obsessive compulsive disorder (OCD), and others), and drug- and alcohol-dependency has been investigated in several studies during the latest decade. For a recent review see Kessler [17]. However, the association between affective disorders and Parkinson's disease (PD) has seldom been in focus.

\section{Comorbidity and Temporal Associations}

Theoretically, it is possible that major affective disorders may share some common pathophysiological mechanisms with PD. For this reason, we wanted to review the epidemiological literature regarding comorbidity between affective disorders and PD to investigate the temporal relationship between the disorders in order to elucidate aetiological causality.

Burke et al. suggested the term "comorbid" in psychiatric epidemiology meaning the presence of more than one specific disorder in a person, in a defined period of time [18]. The present review is particularly concerned with the temporal aspects of the comorbidity between PD and affective disorders, i.e. the probability for patients with affective disorders of developing a neurological 
disorder; and the probability of patients with neurological disease of developing affective disorders.

The temporal association of symptoms are of great importance in everyday clinical situations [19]. The consequences of temporal associations between affective disorder and the neurological disorder are of clinical as well as theoretical importance.

The questions in focus in this review will be:

1) Temporal associations: are there differences in the course of the illness (affective/neurological), depending on whether symptoms of depression are primary or secondary to the neurological disorder? What are the rates of co-occurrence?

2) The use of rating scales in epidemiological studies in identifying risk factors for developing depression in patients with PD. Time relationship is important the choice of rating scale.

3) What is learned from family studies and data from genetic studies, and temporal relationship?

4) And the quintessence: is the comorbid affective disorder a psychological reaction to the distress caused by a severely disabling neurological disease, PD, or is it secondary to the neuro-pathophysiological process of PD itself? Can time-relationship tell us anything on these matters?

To what extent comorbid affective disorder is the result of treatment of PD, was not dealt with in this paper.

\section{SEARCH STRATEGY AND SELECTION CRITERIA}

Data for the overview of the literature for this paper were identified by computerised searches of the MEDLINE and EMBASE databases. In MEDLINE the search terms were: Explode of "Depressive disorder" and "Bipolar disorder" (search of the listed terms and their sub-headings and thereby covering "Affective disorders" as well) and combined with explode of "Parkinson disease". The search included all published articles from 1966 to September 2010. An additional search of the term "Depression" was performed. In the EMBASE the search included all published articles from 1986 to 2010, and the keywords concerning affective disorders were slightly different (manio-depressive, endogenous depression) but the procedure was the same. The searches were combined with the keywords "Temporal relations", "Temporal", and "Time".

Additional articles were identified through manually searching the reference list of retrieved articles. Reviews were consulted and additional manual search was pursued to augment the computer-generated study-base of literature. Books on neurological diseases, e.g. symposia summaries, were consulted to obtain additional information.
The Cochrane Library was consulted for additional references. This search gave no additional references since it was primarily or maybe only based on Medline searches.

\section{RESULTS}

\subsection{Parkinson's Disease (PD)}

We found more than 700 articles; primarily on comorbidity. It soon turned out that there was not published much on bipolar disorder and PD. Many results come from family studies done in the 1990-ies and the 2000ies.

The predominant feature of PD involves disturbances of motor control. The mean age of onset has been reported to be 55 years (two-thirds of the patients were between the ages of 50 and 69) [20,21]. Emotional symptoms have been described since James Parkinson's first description of the disorder in 1817 [22], and depression has been one of the most frequently reported.

The amount of papers on the subject of depression in PD is extensive. Several reviewers have investigated the subject, and in the last decade numerous major reviews were isolated with different foci [10,13,23-35]. These can be divided into reviews on neurobiology $[10,13,24-$ $26,30-32]$, epidemiology $[10,23,25,28,33,35]$, and treatment $[10,27,29,34]$.

\section{Temporal Associations between Depression and PD and Rates of Comorbidity}

As a contribution to the revision of the DSM-III-R [36] category "Psychological Factors Affecting Physical Condition” for DSM-IV [37], McNamara [33], reviewed depression in several neurological conditions (stroke, multiple sclerosis, PD, and epilepsy). Regarding PD it was pointed out that depression could present itself as a complication in PD in several ways. For example it was asked: "Does depression precipitate PD by lowering the reserve of neurotransmitters?" or, "Is depression the first sign of PD, with the motor complications (tremor and cog wheeling) appearing only later as the disease progresses?”

These questions are dealing with the temporal association between affective disorders and the impairment of motor function in patients with PD. McNamara mentioned that these issues were at that moment (1992) unsolved.

Cummings [25], in an extensive and seminal review of the neurobiological literature, found a mean frequency of $40 \%$ (range $4 \%$ to $70 \%$ ) of depression in Parkinson's disease, reported in a period of nearly 70 years (1922 to 1990). Many methodological problems exist in the early studies at least if judged by the standards of today (this was before standardised rating scales, operationalised 
diagnostic criteria etc.). Therefore in nine studies reported in $1987-1990$ a mean frequency of $43 \%$ (range $25 \%$ to $70 \%$ ) was reported with better methodology [25].

The incidence of depression in a population of PD patients has been estimated to be $1.86 \%$ per year [38]. Published estimates of the incidence of depression in the general population are few, and the ones comparable are much lower, maybe only one tenth $(0.14 \%$ per year for men over 50 years, $0.29 \%$ per year for women over 50 years) [39], or from the Lundby study in Sweden, where the incidence rate for people over 40 years was found to be $0.17 \%$ for both sexes [40]. Both figures need though replication with modern methods, as indicated by Dooneief et al. [38].

In a review by Tom and Cummings [34] on pharmacology and treatment of depression in PD, a list of possible risk factors for developing depression in PD was presented. This included: young age, younger age at onset of PD, female gender, right-sided hemi-parkinsonism, and akinesia increased severity of disability, anxiety, and psychosis, which will all be discussed in the following.

Guze and Barrio [28] noted on the aetiology of depression in PD patients that there was no clear consensus on how common it was for mood disorders to precede motor manifestations of PD. Some authors have reported that for the majority of patients psychiatric symptoms begun after the onset of PD [41], but others, using retrospectively collected data, reported that, in the year preceding the diagnosis of PD, the incidence of depression, irritability, and instability of emotions was significantly raised [42-44].

To investigate whether patients with Parkinson's disease were at an increased risk of developing major depression compared with patients with other medical illnesses with a comparable degree of disability, Nilsson et al. [45] conducted a Register linkage study combining the Danish National Hospital Register with the Danish Psychiatric Central Register. Three study cohorts were identified: patients with Parkinson's disease, patients with osteoarthritis, and patients with diabetes. The rate of discharge diagnosis of depression on readmission was estimated with the use of competing risks in survival analysis. The rates were compared with the rates for readmission with a diagnosis of depression for patients with osteoarthritis, and patients with diabetes. The study sample identified 211,245 patients in the Danish hospital registers with one of the index diagnosis. An increased probability of developing a diagnosis of depression was found for both women and men throughout their lifetime when this was compared with the best suitable control groups. No effect of age at onset of Parkinson's disease was found. In the same study it was found that the intensity of developing a depressive episode in PD was found to be statistically significantly elevated compared with osteoarthritis (reference group) during the entire period of PD illness (duration of illness) [45].

In the same study female patients with PD were found to have an estimated intensity of depression of 3.29 (95\% CI: 2.00 - 5.40) compared with male patients with PD. The intensity was elevated for female patients with PD compared with female patients with diabetes or with osteoarthritis. These findings support the hypothesis that depression in patients with Parkinson's disease is a consequence of some kind of brain dysfunction [45]. This suggest a common pathophysiological association between PD and major depression [2].

Nilsson et al. also conducted another case register study of hospitalised patients in Denmark [46] with up to 17 years of observation. In 11,741 patients, with depressive disorder, the risk of later getting diagnosed with PD, was increased 2.2 times (CI 95\% 1.7 - 2.9) compared to 81,380 patients with osteoarthritis. Depression prior to PD diagnosis has been found to have elevated prevalence rates compared with several control groups, including the general population. So far three studies have investigated to what extent PD could develop in patients with affective disorder [46-48] with comparable results.

The duration between a diagnosis of depression and a diagnosis of PD was 5.4 years on average (95\% CI for mean 4.5 - 6.2 years; std. error 0.43 ), in accordance with others [49]. The results indicate that the onset of idiopathic, classic PD is frequently preceded by a prodromal phase lasting from 4 - 6 years [50] and depression could well be one of the symptoms. This suggests that depression could act as a predictor for PD and there is a rather long time interval between incident depression and the origin of the diagnosis of PD. Figure 1 illustrates this. $75 \%$ percentiles are used rather than confidence intervals. It is illustrated that time from depression until admission for PD is longer than time from first admission for mania or suitable control groups, osteoarthritis and diabetes (Nilsson, FM, unpublished data).

There have been contradictory results about the presence of depression in PD and the patient's age at onset of PD. Some found no relationship [51,52], and others found a tendency of patients with PD and depression to be younger at the time of onset of PD symptoms (PD prior to age 55) than non-depressive PD patients $[44,53$, 54]. It has been suggested that PD with depression might constitute a subtype of PD, in which patients are characterised by younger age at onset of PD, less impairment, and a higher frequency of positive family history of PD [44].

Concerning the duration of PD and the rate of depression in PD, most investigators have found no relationship [51,52,55-60]. This is interesting because depression might occur both early and late in PD, and early recognition is in both instances important because of the impact 


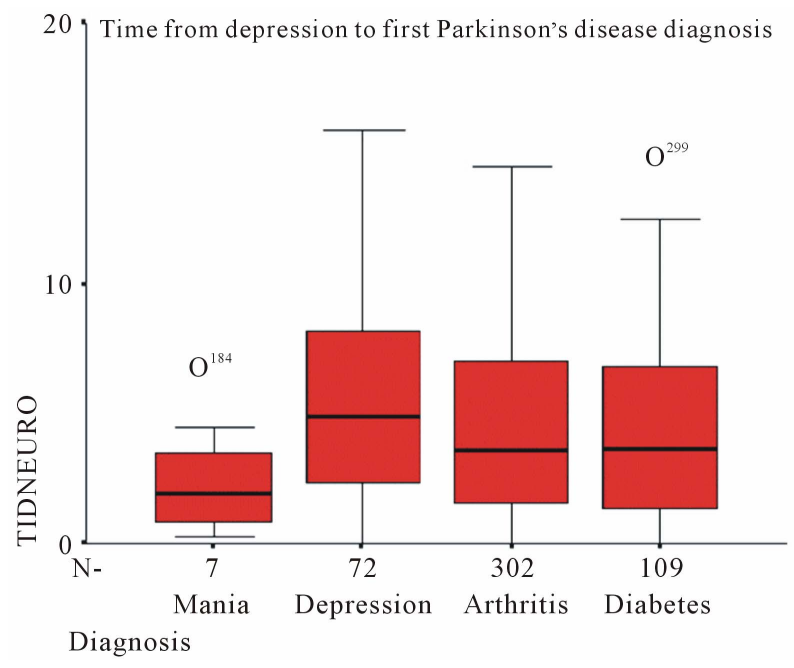

Figure 1. Diagram showing box plots of time from first diagnosis of mania, depression, and two control group diagnoses (osteoarthritis and diabetes) in Danish health Register until first diagnosis of Parkinson's disease in the same registers. Median value and quartiles can be compared. See text. 25\% percent lower and upper quartiles are shown. Solid horizontal line is the median value. 95\% intervals are shown in vertical lines. A few outliers are shown.

on quality of life and even worsening of motor symptoms, that seems to decline faster if depression is present.

Instead of using a mere calendar time since onset of $\mathrm{PD}$, some investigators have also considered staging of PD. As an indicator of the course of the illness, the Hoehn and Yahr staging scale (HY) [21] has been widely used. Some investigators found no relationship between depression scores and HY [55,57] and few reported that depressed PD patients had a significantly more advanced stage of disability than non-depressed PD patients [42, 61]. In a follow up investigation it was found, that patients with major depression at the initial examination, showed a significant faster progression along the stages of PD compared with patients with minor depression or no depression initially [62] (Figure 2).

Activities of Daily Living (ADL) [63] has been used in studying the relationship between depression and severity of functional impairment. In a group of PD patients with "on-off phenomena", depressed PD patients were shown to be more disabled (less independent) than PD patients without depression, and the severity of the depression correlated with the degree of disability [64]. In other groups of PD patients (out-patients in neurological clinic), it was found that depression in later onset PD was strongly associated with the severity of impairment in ADL [42]. However, others have found a weak correlation only $[56,57,65,66]$. There is no consensus on the subject [67], but it seems that PD patients with major depression have a significant faster decline in ADL and a faster progression along the stages of illness compared

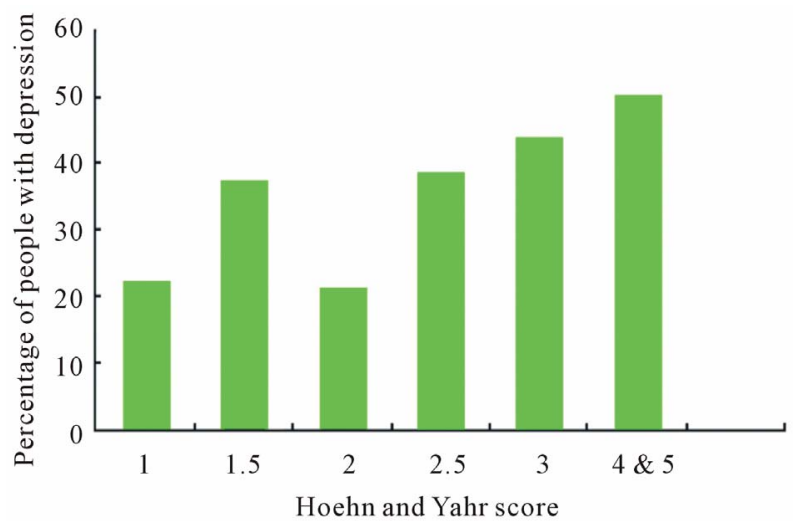

Figure 2. Depression in Parkinson's disease by severity score as defined by Hoen and Yahr. Based on data from Schrag et al. Psychol Med 2004; 31: 65 - 73. Adapted from Rickards, J Neurol Neurosurg Psychiatry 2005; 67: i48 - i52, with permission.

with non-depressed PD patients [68].

Asymmetric left-sided Parkinson's disease was found to be associated with greater rates of symptoms of anxiety and atypical depression in one study only [69] and has not been replicated.

\subsection{Rating Scales and Risk Factors for Depression in PD}

In the quantification of mood changes in $\mathrm{PD}$, the Beck Depression Inventory (BDI) (a self-report symptom rating scale) [70] has been the most widely used instrument. Other instruments in evaluation of depression have been the Hamilton Depression Rating Scale (HDRS) [71], the Zung Depression Questionnaire [72], Montgomery-Åsberg Depression Rating Scale (MADRS) [73]. Diagnostic criteria have been established according to Research Diagnostic Criteria (RDC), American Psychiatric Association's DSM criteria, and WHO's ICD criteria.

The BDI was constructed for measuring the severity of depression in patients with idiopathic depression. Measuring the severity of depressive symptoms in PD with the BDI, the somatic items included in the scale raise questions about its ability to differentiate depression from manifestations of the disease (in this case PD). Most authors discuss this, and two different groups reported that the BDI scores were found to reflect the severity of depressive symptoms in $\mathrm{PD}$ and that it was possible to separate them from symptoms of PD [74-76]. Others found that depression scores in PD, as measured by BDI, were significantly higher than in normal controls, but did not differ from those in control groups of arthritis patients [52]. Depression in PD has been found to be characterised by dysphoria, pessimism and various somatic complaints [56] and less complaints of guilt and self blame $[41,77,78]$. Henderson et al. found that PD patients also had increased measures of comorbidity with 
anxiety [77]. The variance in prevalence of anxiety was primarily explained by the severity of symptoms in depression and not by the severity of the PD illness itself or the dose of levodopa. Consequently, it was suggested that the excess anxiety found in these PD patients was not primarily a psychological reaction to the illness or a side effect of levodopa treatment. Thus, from these and other studies, it appears that anxiety and severe depression are related manifestations of the underlying neurochemical changes related to PD itself [78]. Leentjens et $a l$. has evaluated BDI for use in PD patients and found that with some caution it could be used as a screening instrument and even as a diagnostic tool [79]. A recently published rating scale called Major Depression Inventory (MDI) for measurement of depression in PD has been presented and evaluated as an alternative to the BDI and the Zung scale [80]. No rating scales deals with temporal relationships as such. Further research is needed to evaluate the value of this.

\subsection{Depression and PD in Community Studies}

Very few community-based studies have been published. In general the prevalence of depression has been found to be lower in these studies than in studies conducted in tertiary centres (university clinics). Thus, in a community-based cross-sectional study from Rogaland County in Norway, $7.7 \%$ met the diagnostic criteria for major depression using DSM-III-R among 245 patients with PD. Based on MADRS scores for assessment of severity of symptoms, $5.1 \%$ of the PD patients were found moderately to severely depressed and another $45.5 \%$ had mild depressive symptoms, [59]. In the survey of literature we found one other population based study from Dunedin, New Zealand [60]. Using a relatively rigorous selection procedure they found 73 cases $(16 \%$ refused to participate, $26 \%$ were excluded because of low MMSE score, meaning impaired memory). Two patients were suffering from major depression following DSM-III-R (2.7\%). Larger scale studies are needed to establish more precise estimates of the prevalence in unselected populations [25].

\subsection{Bipolar Disorder and PD}

Only one recently published epidemiological paper with relevant data exist about mania or bipolar disorder and PD [81], as reviewed later.

Additionally, in our review of the literature we found ten case-stories in nine journal articles [82-90]. Some reports deal with manic attacks in PD without relation to drug treatment $[82-84,86,87]$, and some deal with probable drug-induced manic attacks in PD patients treated with apomorphine or levodopa $[85,88,89]$. Only one case story presents a bipolar affective patient who subsequently developed PD. A severe manic episode occurred after initiating levodopa. The manic episode was treated successfully with clozapine, and levodopa dose was even raised afterwards [82].

In our group, in a hospital discharge registry study, based on the Danish population (approximately 5.1 million people), we found in a group of 2007 incident, hospitalised manic or bipolar patients, followed for up to 17 years, that the risk of a subsequent diagnosis of PD was not significantly elevated compared to control groups [46].

In Figure 3 is shown time to survival, i.e. time that passes without PD for four different groups: mania, depression and control groups osteoarthritis and diabetes. There is no significant difference was found between mania and the control groups [46].

\subsection{Family History Studies of Depression in PD and Genetic Studies}

It has been suggested that there may be a variant of PD in which depression is more common, characterised by greater bradykinesia, rigidity, younger age of onset, and a greater probability of a positive family history for PD [28, 44]. The effect of a family history of affective disorder on the risk of developing PD later on has, as far as we know, not been investigated. One twin study was found, although small in sample size (basically case stories) [91].

One study [81] has analysed the family history of PD in a population of psychiatric patients. As part of the Rotterdam Study (a single centre, prospective follow up

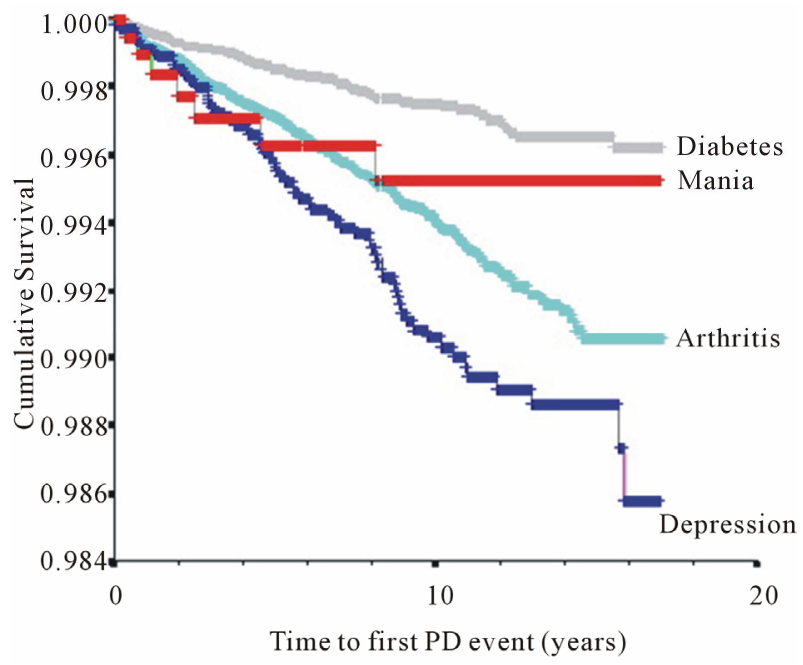

Figure 3. Kaplan-Meier (cumulative survival) plot of the risk of being discharged from a Danish hospital with a diagnosis of Parkinson's disease after an initial diagnosis of manic episode, depressive disorder or a control group diagnosis (osteoarthritis and diabetes). It is shown that a diagnosis of manic episode is not different from the control group osteoarthritis. 
study) a sub group of 329 participants were identified as patients who had ever been treated by a psychiatrist for depression (patient self report). Data on the family history in first-degree relatives were collected, including psychiatric disease, dementia, and PD (self report). A tendency of increased risk of PD (however, not significant) was reported in families of those patients with bipolar depression (odds ratio 1.87, 95\% CI: 0.65 - 5.34, NS), but not in families of patients with unipolar depression (odds ratio $0.67,95 \%$ CI: 0.37 - 1.20, NS), suggesting that an association within families might be limited to bipolar disorders only (see later). In general, no clear relationship to family history of affective disorder, or a personal history of previous depressive episodes have been found $[25,30]$.

A familial autosomal dominant form of parkinsonism and severe depression with an early onset, rapid progression leading to an early death, and in some families, additionally respiratory problems (alveolar hypoventilation), were summarised from five distinct families by Bhatia et al. [92]. There was no or only brief response to levodopa treatment. The syndrome was associated with a distinctive post-mortem neuropathology showing devastation of the substantia nigra (with only rare Lewy bodies), less conspicuous and inconstant changes in other brainstem nuclei, and sometimes gliosis in the caudate and globus pallidus. In idiopathic PD there is no autosomal inheritance, and Lewy bodies are characteristically shown in the remaining neurons at autopsy [20]. Nevertheless, this syndrome could be aetiologically interesting in studying the temporal relationship between depression and PD. Newer studies have though elucidated smaller groups of PD patients with susceptibility genes, alpha synuclein, leucine rich repeat kinase 2 (LRRK-2), and glucocerebrosidase (GBA), and together with others i.e. parkin, are especially in younger patients an important causal factor [13], but still small in numbers.

The frequency and clinical correlates of neuropsychiatric symptoms in patients with PD, with and without dementia, and in those with dementia with Lewy bodies (DLB) has been investigated by Aarsland et al. [93]. The frequency of major depression, and less-than-major depression, did not differ significantly between the three groups.

In a large population based historical cohort study it was found that depressive and anxiety disorders may share familial susceptibility factors with PD [94]. Caution should though be taken because of the sampling technique used. Depressive disorders were relied on both medical records and personal interviews (even by telephone), and consistency was not evident for probands and controls. This could give rise to a kind Berkson's bias $[95,96]$. Interestingly it was found that for younger PD patients' relatives there seems to be an increased risk of depression. This could be of genetic origin [94], but other possibilities can not be entirely ruled out.

\subsection{Family History Studies of Bipolar Disorder in PD}

This has only been scarcely studied.

In a population based study by Fahim et al. [81], patients with bipolar disorder were studied with the use of data from the Rotterdam Study [97]. Among the 10,275 eligible subjects, 7983 (78\%) were evaluated, and data on their history of psychiatric disorders was available for 6596 (based on self-reports). One of the questions asked was whether the subject had ever been treated for depression by a psychiatrist. If so, a detail set of data was requested on the diagnosis, age at onset, number of affective episodes, and treatment. Totally 329 patients were identified (26 with bipolar disorder). All participants were asked about their history of psychiatric disease and family history in first-degree relatives. Separate analyses were made for patients with unipolar and patients with bipolar disorder, and odds ratios were calculated. These have previously been mentioned in this paper. It was found that the risk of bipolar disorder tended to be increased for individuals with a positive family history of PD. In the work by Arabia et al. it was also investigated if the risk of bipolar disorder among first-degree relatives of patients with PD was elevated compared with relatives of controls. No elevated hazard ratio was found [94]. No association between bipolar disorder and family history of PD was found.

It seems from these studies that mania and hypomania are rare in PD, but also that patients who previously had signs of mania or hypomania may experience an acute exacerbation when given dopaminergic drugs [98].

\section{DISCUSSION}

\subsection{Temporal Associations}

The contemporary neurobiological literature on PD and affective disorders show that the prevalence of depression in PD is elevated compared with the general population. In several cases up to a mean of $40-43$ percent of patients with PD has been found to suffer from depression [25] versus 14.9 percent in crude prevalence of lifetime depression in the US National Comorbidity Survey [17]. In the relatively few community studies published, the prevalence of comorbidity between depression and PD has in general been reported to be lower. This reflects methodological differences, but also a relative difference between depression in highly selected samples and depression in the community, giving "an estimate" of the amount of patients in the community who never seek treatment. A "need of treatment" assessment in the gen- 
eral population is warranted, as suggested by Wittchen [99].

It has to be emphasised that the reverse association, the risk for patients with affective disorder of developing a neurological disorder, has been only scarcely investigated. In patients with affective disorders we located three studies [46-48], all done in 2000-ies and in three different populations [49]. From these three huge register studies it might be concluded that a neurobiological link between the two disorders is possible.

Most case-control studies quoted in this review were small in sample sizes and most frequently conducted in tertiary centres (university clinics) with the risk of introducing a selection bias $[44,47,52,57,64]$. The majority of the studies had a relatively short follow-up time, at least compared to the long lasting conditions in focus here; (all cases of PD last in fact for life). Survival analysis was only rarely used. A special topic to be very careful about, concerning comorbidity is Berkson's fallacy or bias; in which persons with two conditions are more likely to be hospitalised or seek treatment. This could lead to artefact associations [100,101], and should be avoided by for example symmetric exclusion criteria for cases and controls, or careful selection of control subjects independently of exposure status and in some cases a stratified analysis. Survival analysis is the proper way to analyse time relationships in comorbidity studies.

PD has been investigated concerning depressive disorders and comorbidity. Comorbidity between bipolar disorder and neurological diseases remains to be illuminated, in all areas of interest, but from the available data there seems to be strong evidence in favour of a neurobiological connection between the two disorders of yet unknown nature. A hypothesis of a excitotoxin mechanism in the basal ganglia has been proposed for affective disorders [102]. Recently a hypothesis of excitotoxicity in PD pathogenesis has been proposed by Beal [24]. This was in accordance with hypothesis concerning other brain diseases, e.g. Huntington's disease [102].

One could speculate, whether the underlying and yet unknown mechanism in depression, comorbid with neurological disorders, is a cascade-like process that could be triggered in several different ways (or in different points of the evolving process) and lead to the same endpoint, namely depression [103].

An important finding, using PET-scanning, was a paralimbic frontal lobe glucose hypometabolism in patients with depression associated with PD compared with non-depressed patients with PD [31]. This was in accordance with findings from studies concerning patients with primary depression $[104,105]$. This means at least a resemblance in between the two conditions in this imaging technique.

Another elegant imaging support was found using transcranial midbrain sonography. Walther et al. [16] found in a group idiopathic PD patients, which was divided in a group with depression and a group without depression that, when they were compared with patients with primary depression and a age matched non-PD, non-depressed control group, that the finding of substantia nigra hyperechogenicity [15], which is characteristic for idiopathic PD, is also frequently seen in depressive disorders [16]. This may support the epidemiological data, but further investigations are mandatory.

\subsection{Neurobiological Results}

From the literature search several landmark theoretical papers on PD and depression were found, both concerning clinically relevant [25] and molecular and cellular hypotheses $[24,106,107]$. To evaluate these hypotheses one has to see them in the light of the clinical theories on primary depression $[103,108]$ and bipolar disorder [109]. In this context the molecular and cellular hypothesis become vast in numbers and often evasive in nature, see [110-113] and [114] with comments by Robert Post [115]. We have limited ourselves to evaluate hypothesis that involves the limbic system and the basal ganglia, in an attempt to integrate results from secondary depression in neurological diseases.

CT-scans, MRI and functional brain imaging like PET, have in lesion-and-deficit studies supported an association between lesions disrupting frontostriatal or paralimbic pathways and depressed mood [10,116]. In both PD and Huntington's disease (HD), orbitofrontal circuit dysfunction appears to be linked to depression. The orbitofrontal circuit is carrying projections from the basal ganglia to the orbitofrontal cortex, a neocortical part of the limbic system [117]. In PET studies PD patients with depression show significantly lower metabolism both in the orbito-inferior frontal cortex and the head of the caudate nucleus compared with PD patients without depression [118]. The mechanisms underlying mood disorders in PD are not well understood. In patients with HD a selective involvement of limbic and prefrontal striatal pathway as a result of caudate, basal amygdaloid, or frontal cortical degeneration has been proposed [119]. On the basis of these results the "Excitotoxin-b hypothesis” has been proposed [102]. This offers explanations for the most of the aforementioned results. But if a similar mechanism is involved in depressed patients with PD remains to be solved [46,67,120,121]. A mechanism like the excitotoxin hypothesis seems to "fit" with the epidemiological data. This stresses that an early detected defect in prefrontal cortex may give rise to earlier diagnosis of depression in PD.

Recently an algorithm for clinical prediction of PD according to the neuropathological stage (Braak stages) 
has been published [122]. The purpose was to predict development of PD in earlier stages to be able to plan for better neuroprotection in the future. In Figure 4 I have tried to present the results in a schematic form. It can be seen that depression can develop in pre-motoric stage 2 where the alpha-synuclein deposition is merely in lower brain regions. Depression should be evaluated with rating scales as e.g. suggested by Bech [123]. Again an earlier diagnosis of depression in patients with PD would be of great importance to the patients. And timing is the important issue, because there will be a gap in time should be possible to narrow.

\subsection{Rating Scales}

The use of psychometric rating scales is an important matter in these studies. It has been mentioned in a paper concerning MS, that the Montgomery-Åsberg Depression scale (MADRS) has some advantages in a comorbidity study with neurological patients, because it has less items with physical symptoms (i.e. measuring merely psychological problems) [59]. However, the scale's content validity and inter-rater reliability has been questioned [123].

It could not be recommended to use sub-scales of the existing depression rating scales, since the validation of the sub-scale is a difficult task, and comparisons between studies become almost impossible.

A new alternative for a self rating scale, the Major Depression Inventory (MDI), has been suggested by Bech et al. [80] for evaluation of PD patients. The MDI

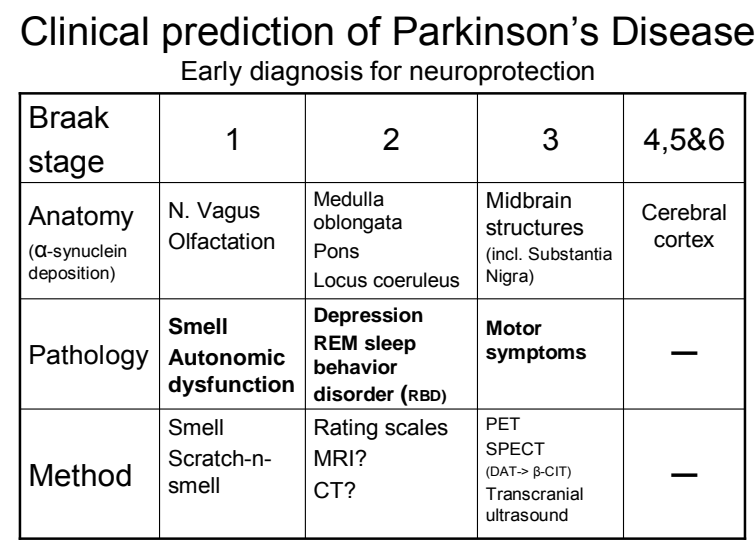

After: Postuma et al JNNP 2010

Figure 4. Results from a review on clinical prediction of Parkinson's disease, presented in schematic form, showing the Braak neuropathological stages of progression in Parkinson's disease and the corresponding anatomical, clinical pathological features (symptoms) and the suggested methods of investigation in the different Braak stages. The purpose is earlier diagnosis to improve treatment. In stage 4, 5, and 6 no additional methods are suggested, since diagnosis in these stages often is self evident (more severe PD). Adapted after Postuma et al. JNNP, 2010. was found superior to the analogue Zung scale [72], and was designed to measure the frequency of symptoms. The MDI contains the items covering both ICD-10 and DSM-IV symptoms for unipolar/major depression, making it possible to diagnose depression in PD in both the ICD-10 and the DMS-IV systems. To our knowledge, the validity of the scale has also been studied in other populations than a clinical sample of patients with PD [80], and has been validated in English, Danish, Swedish, German, Greek, and Dutch .

Both The BDI and the HDRS partly rely on somatic symptoms (e.g., fatigue or loss of energy, weight loss, insomnia, concentration difficulties, etc.), which are also part of the neurological deficits. The MDI could be an alternative. Both BDI and HDRS have recently been evaluated as tools for measuring Depression in patients with PD [79,124].

All rating scales are dependent on experienced users and training of the personnel using them. The more experienced-the earlier the affective disorder will be detected.

\subsection{Family Studies and Genetics}

From family studies it was learned that predominantly younger PD patients have a family history of depression. For bipolar disorder the opposite was the case. No relationship was found except that treatment with dopamine containing drugs can give rise to exacerbation [94].

\section{CONCLUSIONS}

\section{Implications and Recommendations}

The overall goal of this review was to discuss comorbidity between affective disorder and PD. It can from our review be concluded that comorbidity between PD and affective disorder was higher than expected in the majority of the studies. However, the temporal associations between the disorders are not fully elucidated.

There is some evidence that the course of PD for patients with PD and a comorbid depression is impaired compared to patients with PD without comorbid affective disorder. The reverse situation, whether the course of affective disorders is altered by the comorbid neurological condition (PD), has been less well investigated. In depressed patients (major depression) with accompaning medical (non CNS) illnesses (DSM-III, axis I, II, or III—other than affective disorder), the course and recovery rate were less favourable, in the populations investigated, than in "pure depression" [125]. From the studies of the Copenhagen group it could be learned that depression could well be a predictor of PD and a neurobiological "link" between the disorders could not be excluded $[45,46,49]$. 
As stated in the introduction several scenarios concerning PD and affective disorder comorbidity may theoretically occur:

1) PD and affective disorders (depression or mania) co-occur, i.e. both disorders present themselves at the same point of time.

2) Affective symptoms or disorder (depressive or manic) may be the first to occur, i.e. precursor of PD. Hence, in this scenario, there would be no time interval between the two disorders.

3) Affective symptoms or disorder (depressive or manic) may be a predictor of a subsequent diagnosis of PD. Hence, in this scenario; there would be a symptom-free interval between the two disorders.

4) Neurological symptoms and signs of PD may be the first to occur, i.e. precursor of affective disorder. Hence, in this scenario, there would be no time interval between the two disorders.

5) Neurological symptoms and signs of PD may be a predictor of subsequent affective disorder. Hence, in this scenario, there would be a free time interval between the two disorders.

At least for some cases the scenario 3 is the most probable explanation and likewise scenario 5 is the most probable for some cases of patients with PD. From this review it could be learned that the temporal aspects strongly suggest a neurobiological association exists between affective disorder and PD.

It is therefore necessary to investigate these aspects further in "large scale" epidemiological comorbidity studies with the proper rating scales. There is a need for prospective longitudinal studies including large cohorts of patients with affective disorder and large cohorts of patients with neurological disorders [99] including cases of patients with dementia to account for $20 \%$ to $30 \%$ of PD patients who develop dementia during the course of the PD illness [126]. Additionally, there is a need for further family and genetic studies.

Some of these relationships have been investigated in case register studies, e.g. by linkage of the Danish National Hospital Register including somatic disorders (Lands Patient Registeret, LPR), and the Danish Psychiatric Central Register (PCR) including psychiatric disorders as done in the studies from our research institute. Recently we extended the studies with linkage with a prescription database, from the Danish Medicines Agency. This was primarily done to control for the effect of treatment given to the patients in studying the comorbid conditions [127,128].

In 1817 James Parkinson noted a relationship between mood disorders and "The Shaking Palsy" [22]. Of course much has been elucidated in our understanding of the pathogenesis of the comorbidity of the diseases, but still much needs to be further investigated.
For general practitioners, psychiatrists, geriatricians, and neurologists these new findings will lead to a better understanding of the diseases and eventually a better treatment of patients with complicated comorbid conditions. For clinicians it is important to realise that a depressive disorder in old age is of course not a neurological condition, but that eventually some of our patients with depression will develop a neurological disease such as Parkinson's disease, and treatment of this condition may be initiated earlier if the physician remembers this possibility. This could have great impact for many elderly patients. Already St. Augustine realised that time is a difficult concept to understand. The quintessence being: "Timing is important!"

\section{ACKNOWLEDGEMENTS}

The author thanks Ms. Christine Sweeney Hansen for language corrections. The Theodore and Vada Stanley Foundation (USA) supported this study. Professor Lars Vedel Kessing, Rigshospitalet, Copenhagen made numerous suggestions on an earlier draft of this paper, for which he is gratefully thanked.

\section{REFERENCES}

[1] Aarsland, D., Larsen, J.P., Lim, N.G., Janvin, C., Karlsen, K., Tandberg, E. and Cummings, J.L. (1999) Range of neuropsychiatric disturbances in patients with Parkinson's disease. Journal of Neurology, Neurosurg Psychiatry, 67, 492-496. doi:10.1136/jnnp.67.4.492

[2] Lieberman, A. (2006) Depression in Parkinson's disease -A review. Acta Neurologica Scandinavica, 113, 1-8. doi:10.1111/j.1600-0404.2006.00536.x

[3] Schrag, A. (2004) Psychiatric aspects of Parkinson's disease-An update. Journal of Neurology, 251, 795-804.

[4] Aarsland, D., Bronnick, K., Alves, G., Tysnes, O.B., Pedersen, K.F., Ehrt, U. and Larsen, J.P. (2009) The spectrum of neuropsychiatric symptoms in patients with early untreated Parkinson's disease. Journal of Neurology Neurosurgery \& Psychiatry, 80, 928-930. doi:10.1136/jnnp.2008.166959

[5] Shulman, L.M., Taback, R.L., Rabinstein, A.A. and Weiner, W.J. (2002) Non-recognition of depression and other non-motor symptoms in Parkinson's disease. Parkinsonism \& Related Disorders, 8, 193-197. doi:10.1016/S1353-8020(01)00015-3

[6] Chaudhuri, K.R. and Schapira, A.H. (2009) Non-motor symptoms of Parkinson's disease: Dopaminergic pathophysiology and treatment. Lancet Neurology, 8, 464-474. doi:10.1016/S1474-4422(09)70068-7

[7] Buchel, C. and Dolan, R.J. (2000) Classical fear conditioning in functional neuroimaging. Current Opinion in Neurobiology, 10, 219-223. doi:10.1016/S0959-4388(00)00078-7

[8] Soares, J.C. and Mann, J.J. (1997) The anatomy of mood disorders-Review of structural neuroimaging studies. Biological Psychiatry, 41, 86-106. 


\section{doi:10.1016/S0006-3223(96)00006-6}

[9] Videbech, P. (1997) MRI findings in patients with affective disorder: A meta-analysis. Acta Psychiatrica Scandinavica, 96, 157-168. doi:10.1111/j.1600-0447.1997.tb10146.x

[10] Soares, J.C. and Mann, J.J. (1997) The functional neuroanatomy of mood disorders. Journal of Psychiatric Research, 31, 393-432. doi:10.1016/S0022-3956(97)00016-2

[11] Kennedy, S.H., Javanmard, M. and Vaccarino, F.J. (1997) A review of functional neuroimaging in mood disorders: Positron emission tomography and depression. Canadian Journal of Psychiatry, 42, 467-475.

[12] Au, W.L., Adams, J.R., Troiano, A. and Stoessl, A.J. (2006) Neuroimaging in Parkinson's disease. Journal of Neural Transmission Supplementa, 70, 241-248.

[13] Lees, A.J., Hardy, J. and Revesz, T. (2009) Parkinson's disease. Lancet, 373, 2055-2066. doi:10.1016/S0140-6736(09)60492-X

[14] Becker, T., Becker, G., Seufert, J., Hofmann, E., Lange, K.W., Naumann, M., Lindner, A., Reichmann, H., Riederer, P., Beckmann, H. and Reiners, K. (1997) Parkinson's disease and depression: Evidence for an alteration of the basal limbic system detected by transcranial sonography. Journal of Neurology, Neurosurgery \& Psychiatry, 63, 590-596. doi:10.1136/jnnp.63.5.590

[15] Walter, U., Behnke, S., Eyding, J., Niehaus, L., Postert, T., Seidel, G. and Berg, D. (2007) Transcranial brain parenchyma sonography in movement disorders: State of the art. Ultrasound in Medicine and Biology, 33, 15-25. doi:10.1016/j.ultrasmedbio.2006.07.021

[16] Walter, U., Hoeppner, J., Prudente-Morrissey, L., Horowski, S., Herpertz, S.C. and Benecke, R. (2007) Parkinson's disease-like midbrain sonography abnormalities are frequent in depressive disorders. Brain, 130, 1799-1807. doi:10.1093/brain/awm017

[17] Kessler, R.C. (1999) Comorbidity of unipolar and bipolar depression with other psychiatric disorders in a general population survey. In: Tohen, M., Ed., Comorbidity in Affective Disorders. Marcel Dekker, Inc., New York, $1-27$.

[18] Burke, J.D., Wittchen, H.-U., Regier, D.A. and Sartorius, N. (1990) Extracting information from diagnostic interviews on co-occurrence of symptoms of anxiety and depression. In: Maser, J.D. and Cloninger, C.R., Eds., Comorbidity of Mood and Anxiety Disorders, American Psychiatric Press, Inc., Washington DC, 649-667.

[19] Judd, L.L. and Kunovac, J.L. (1998) Clinical characteristics and management of unipolar depressive disorders comorbid with neurological disorders. Neuropsychobiology, 37, 84-87. doi:10.1159/000026483

[20] Lishman, W.A. (1998) Organic psychiatry-The psychological consequences of cerebral disorder. Blackwell Science, Oxford.

[21] Hoehn, M. and Yahr, M.D. (1967) Parkinsonism: Onset, progression, and mortality. Neurology, 17, 427-442.

[22] Parkinson, J. (1817) An essay on the shaking palsy. Sherwood, Neely, and Jones, London.
[23] Bader, J.P. and Hell, D. (1998) Parkinson's disease and depression. Fortschritte-der-Neurologie-Psychiatrie, 66, 303312.

[24] Beal, M.F. (1998) Excitotoxicity and nitric oxide in Parkinson's disease pathogenesis. Annals of Neurology, 44, S110-S114.

[25] Cummings, J.L. (1992) Depression and Parkinson's disease: A review. American Journal of Psychiatry, 149, 443-454.

[26] Cummings, J.L. (1993) The neuroanatomy of depression. Journal of Clinical Psychiatry, 54, 14-20.

[27] Factor, S.A., Molho, E.S., Podskalny, G.D. and Brown, D. (1995) Parkinson's disease: Drug-induced psychiatric states. Advances in Neurology, 65, 115-138.

[28] Guze, B.H. and Barrio, J.C. (1991) The etiology of depression in Parkinson's disease patients. Psychosomatics, 32, 390-395. doi:10.1016/S0033-3182(91)72039-2

[29] Lieberman, A. (1998) Managing the neuropsychiatric symptoms of Parkinson's disease. Neurology, 6, S33-S38.

[30] Marsh, L. (2000) Neuropsychiatric aspects of Parkinson's disease. Psychosomatics, 41, 15-23. doi:10.1016/S0033-3182(00)71169-8

[31] Mayberg, H.S. and Solomon, D.H. (1995) Depression in Parkinson's disease: A biochemical and organic viewpoint. Advance in Neurology, 65, 49-60.

[32] Mayeux, R. (1990) Parkinson's disease: A review of cognitive and psychiatric disorders. Neuropsychiatry, Neuropsychology and Behavioral Neurology, 3, 3-14.

[33] McNamara, M.E. (1991) Psychological factors affecting neurological conditions. Depression and stroke, multiple sclerosis, Parkinson's disease, and epilepsy. Psychosomatics, 32, 255-267.

doi:10.1016/S0033-3182(91)72063-X

[34] Tom, T. and Cummings, J.L. (1998) Depression in Parkinson's disease. Pharmacological characteristics and treatment. Drugs Aging, 12, 55-74. doi:10.2165/00002512-199812010-00006

[35] Haltenhof, H. and Schroter, C. (1994) Depression in Parkinson disease. A literature review (in German). Fortschritte der Neurologie-Psychiatrie, 62, 94-101. doi:10.1055/s-2007-996660

[36] American Psychiatric Association (APA) (1987) Diagnostic and statistical manual of mental disorders. 3rd Edition, American Psychiatric Association Press, Washington DC.

[37] American Psychiatric Association (APA) (1994) Diagnostic and statistical manual of mental disorders. 4th Edition, American Psychiatric Association Press, Washington DC.

[38] Dooneief, G., Mirabello, E., Bell, K., Marder, K., Stern, Y. and Mayeux, R. (1992) An estimate of the incidence of depression in idiopathic Parkinson's disease. Archives of Neurology, 49, 305-307. doi:10.1001/archneur.1992.00530270125028

[39] Murphy, J.M., Olivier, D.C., Monson, R.R., Sobol, A.M. and Leighton, A.H. (1988) Incidence of depression and anxiety: The stirling county study. American Journal of 
Public Health, 78, 534-540. doi:10.2105/AJPH.78.5.534

[40] Essen-Möller, E. and Hagnell, O. (1961) The frequency and risk of depression whitin a rural population group in scania. Acta Psychiatrica Scandinavica, 162, 28-32.

[41] Schiffer, R.B., Kurlan, R., Rubin, A. and Boer, S. (1988) Evidence for atypical depression in Parkinson's disease. American of Journal of Psychiatry, 145, 1020-1022.

[42] Starkstein, S.E., Preziosi, T.J., Bolduc, P.L. and Robinson, R.G. (1990) Depression in Parkinson's disease. The Journal of Nervous and Mental Disease, 178, 27-31. doi:10.1097/00005053-199001000-00005

[43] Mayeux, R., Williams, J.B., Stern, Y. and Cote, L. (1984) Depression and Parkinson's disease. Advances in Neurology, 40, 241-250.

[44] Santamaria, J., Tolosa, E. and Valles, A. (1986) Parkinson's disease with depression: A possible subgroup of idiopathic Parkinsonism. Neurology, 36, 1130-1133.

[45] Nilsson, F.M., Kessing, L.V., Sørensen, T.M., Andersen, P.K. and Bolwig, T.G. (2002) Major depressive disorder in Parkinson's disease. A register-based study. Acta Psychiatrica Scandinavica, 106, 202-211. doi:10.1034/j.1600-0447.2002.02229.x

[46] Nilsson, F.M., Kessing, L.V. and Bolwig, T.G. (2001) Increased risk of developing Parkinson's disease for patients with major affective disorder: A register study. Acta Psychiatrica Scandinavica, 104, 380-386. doi:10.1034/j.1600-0447.2001.00372.x

[47] Shiba, M., Bower, J.H., Maraganore, D.M., McDonnell, S.K., Peterson, B.J., Ahlskog, J.E., Schaid, D.J. and Rocca, W.A. (2000) Anxiety disorders and depressive disorders preceding Parkinson's disease: A case-control study. Movement Disorders, 15, 669-677. doi:10.1002/1531-8257(200007)15:4<669::AID-MDS101 1>3.0.CO;2-5

[48] Schuurman, A.G., Van Den Akker, M., Ensinck, K.T., Metsemakers, J.F., Knottnerus, J.A., Leentjens, A.F. and Buntinx, F. (2002) Increased risk of Parkinson's disease after depression: A retrospective cohort study. Neurology, 58, 1501-1504.

[49] Nilsson, F.M. (2010) Depression as a risk factor for Parkinson's disease? www.neurology.org/cgi/eletters/58/10/15012002

[50] Gonera, E.G., Van’t Hof, M., Berger, H.J., Van Weel, C. and Horstink, M.W. (1997) Symptoms and duration of the prodromal phase in Parkinson's disease. Movement Disorders, 12, 871-876. doi:10.1002/mds.870120607

[51] Horn, S. (1974) Some psychological factors in Parkinsonism. Journal of Neurology, Neurosurgy \& Psychiatry, 37, 27-31. doi:10.1136/jnnp.37.1.27

[52] Gotham, A.M., Brown, R.G. and Marsden, C.D. (1986) Depression in Parkinson's disease: A quantitative and qualitative analysis. Journal of Neurology, Neurosurgery \& Psychiatry, 49, 381-389. doi:10.1136/jnnp.49.4.381

[53] Starkstein, S.E., Berthier, M.L., Bolduc, P.L., Preziosi, T.J. and Robinson, R.G. (1989) Depression in patients with early versus late onset of Parkinson's disease. $\mathrm{Neu}$ rology, 39, 1441-1445.
[54] Kostic, V.S., Filipovic, S.R., Lecic, D., Momcilovic, D., Sokic, D. and Sternic, N. (1994) Effect of age at onset on frequency of depression in Parkinson's disease. Journal of Neurology, Neurosurgery \& Psychiatry, 57, 1265-1267. doi:10.1136/jnnp.57.10.1265

[55] Bieliauskas, L.A. and Glantz, R.H. (1989) Depression type in Parkinson disease. Journal of Clinical and Experimental Neuropsychology, 11, 597-604. doi:10.1080/01688638908400918

[56] Brown, R.G., MacCarthy, B., Gotham, A.M., Der, G.J. and Marsden, C.D. (1988) Depression and disability in Parkinson's disease: A follow-up of 132 cases. Psychological Medicine, 18, 49-55. doi:10.1017/S0033291700001872

[57] Ehmann, T.S., Beninger, R.J., Gawel, M.J. and Riopelle, R.J. (1990) Depressive symptoms in Parkinson's disease: A comparison with disabled control subjects. Journal of Geriatric Psychiatry and Neurology, 3, 3-9. doi:10.1177/089198879000300102

[58] Warburton, J.W. (1967) Depressive symptoms in Parkinson patients referred for thalamotomy. Journal of Neurology, Neurosurgery \& Psychiatry, 30, 368-370. doi:10.1136/jnnp.30.4.368

[59] Tandberg, E., Larsen, J.P., Aarsland, D. and Cummings, J.L. (1996) The occurrence of depression in Parkinson's disease. A community-based study. Archives of Neurology, 53, 175-179. doi:10.1001/archneur.1996.00550020087019

[60] Hantz, P., Caradoc, D.G., Caradoc, D.T., Weatherall, M. and Dixon, G. (1994) Depression in Parkinson's disease. American Journal of Psychiatry, 151, 1010-1014.

[61] Huber, S.J., Paulson, G.W. and Shuttleworth, E.C. (1988) Depression in Parkinson's disease. Neuropsychiatry, Neuropsychology and Behavioral Neurology, 1, 47-51.

[62] Starkstein, S.E., Mayberg, H.S., Leiguarda, R., Preziosi, T.J. and Robinson, R.G. (1992) A prospective longitudenal study of depression, cognitive decline, and physical impairments in patients with Parkinson's disease. Journal of Neurology, Neurosurgery \& Psychiatry, 55, 377-382. doi:10.1136/jnnp.55.5.377

[63] Mahony, F. and Barthel, D. (1965) Functional evaluation: The Barthel index. Maryland State Medical Journal, 14, 61-65.

[64] Cantello, R., Gilli, M., Riccio, A. and Bergamasco, B. (1986) Mood changes associated with "end-of-dose deterioration" in Parkinson's disease: A controlled study. Journal of Neurology, Neurosurgery \& Psychiatry, 49, 1182-1190. doi:10.1136/jnnp.49.10.1182

[65] Cole, S.A., Woodard, J.L., Juncos, J.L., Kogos, J.L., Youngstrom, E.A. and Watts, R.L. (1996) Depression and disability in Parkinson's disease. The Journal of Neuropsychiatry and Clinical Neuroscience, 8, 20-25.

[66] Mindham, R.H., Marsden, C.D. and Parkes, J.D. (1976) Psychiatric symptoms during l-dopa therapy for Parkinson's disease and their relationship to physical disability. Psychological Medicine, 6, 23-33. doi:10.1017/S0033291700007467

[67] Starkstein, S.E. and Merello, M. (2002) Psychiatric and 
cognitive disorders in Parkinson's disease. Cambridge University Press, Cambridge.

[68] Rickards, H. (2005) Depression in neurological disorders: Parkinson's disease, multiple sclerosis, and stroke. Journal of Neurology, Neurosurgery \& Psychiatry, 76, i48i52. doi:10.1136/jnnp.2004.060426

[69] Fleminger, S. (1991) Left-sided Parkinson's disease is associated with greater anxiety and depression. Psychological Medicine, 21, 629-638. doi:10.1017/S0033291700022261

[70] Beck, A.T., Ward, C.H., Mendelson, M., Mock, J. and Erbaugh, J. (1961) An inventory for measuring depresssion. Archives of General Psychiatry, 4, 561-571. doi:10.1001/archpsyc.1961.01710120031004

[71] Hamilton, M. (1960) A rating scale for depression. Journal of Neurology, Neurosurgery \& Psychiatry, 23, 56-62. doi:10.1136/jnnp.23.1.56

[72] Zung, W.K. (1965) A self-rating depression scale. Archives of General Psychiatry, 12, 63-70. doi:10.1001/archpsyc.1965.01720310065008

[73] Montgomery, S.A. and Asberg, M. (1979) A new depression scale designed to be sensitive to change. British Journal of Psychiatry, 134, 382-389. doi:10.1192/bjp.134.4.382

[74] Levin, B.E., Llabre, M.M. and Weiner, W.J. (1988) Parkinson's disease and depression: Psychometric properties of the Beck Depression Inventory. Journal of Neurology, Neurosurgery \& Psychiatry, 51, 1401-1404. doi:10.1136/jnnp.51.11.1401

[75] Starkstein, S.E., Preziosi, T.J. and Forrester, A.W. and Robinson, R.G. (1990) Specificity of affective and autonomic symptoms of depression in Parkinson's disease. Journal of Neurology, Neurosurgery \& Psychiatry, 53, 869-873. doi:10.1136/jnnp.53.10.869

[76] Starkstein, S.E. and Mayberg, H.S. (1993) Depression in Parkinson's disease. In: Starkstein, S.E. and Robinson, R.G., Eds., Depression in Neurological Disease, The John Hopkins University Press, Baltimore, 97-116.

[77] Henderson, R., Kurlan, R., Kersun, J.M. and Como, P. (1992) Preliminary examination of the comorbidity of anxiety and depression in Parkinson's disease. The Journal of Neuropsychiatry and Clinical Neuroscience, 4, 257264.

[78] Menza, M.A., Robertson, H.D. and Bonapace, A.S. (1993) Parkinson's disease and anxiety: Comorbidity with depression. Biological Psychiatry, 34, 465-470. doi:10.1016/0006-3223(93)90237-8

[79] Leentjens, A.F., Verhey, F.R., Luijckx, G.J. and Troost, J. (2000) The validity of the beck depression inventory as a screening and diagnostic instrument for depression in patients with Parkinson's disease. Movement Disorders, 15, 1221-1224. doi:10.1002/1531-8257(200011)15:6<1221::AID-MDS10 24>3.0.CO;2-H

[80] Bech, P. and Wermuth, L. (1998) Applicability and validity of the major depression inventory in patients with Parkinson's disease. Nordic Journal of Psychiatry, 52, 305-309.
[81] Fahim, S., Van-Duijn, C.M., Baker, F.M., Launer, L., Breteler, M.M.B., Schudel, W.J. and Hofman, A. (1998) A study of familial aggregation of depression, dementia and Parkinson's disease. European Journal of Epidemiology, 14, 233-238. doi:10.1023/A:1007488902983

[82] Alcantara, L.A., Ortega, R., Morcillo, L. and Barcia, D. (1997) Concomitant bipolar disorder and Parkinson disease treated with clozapine. Psiquis, 18, 41-43.

[83] Kim, E., Zwil, A.S., McAllister, T.W., Glosser, D.S., Stern, M. and Hurtig, H. (1994) Treatment of organic bipolar mood disorders in Parkinson's disease. The Journal of Neuropsychiatry and Clinical Neuroscience, 6, 181184.

[84] Larmande, P., Palisson, E., Saikali, I. and Maillot, F. (1993) Disappearance of akinesia of Parkinson disease during a manic attack. Revista de Neurologia, 149, 557558.

[85] Przedborski, S., Liard, A. and Hildebrand, J. (1992) Induction of mania by apomorphine in a depressed Parkinsonian patient. Movement Disorders, 7, 285-287. doi:10.1002/mds.870070318

[86] Yoash, G.R. (1991) Behavioral management of a bipolar Parkinson patient. Clinical Gerontology, 11, 69-73.

[87] Atre, V.N. and Jampala, V.C. (1988) Electroconvulsive therapy in Parkinsonism with affective disorder. British Journal of Psychiatry, 152, 55-58. doi:10.1192/bjp.152.1.55

[88] Harsch, H.H., Miller, M. and Young, L.D. (1985) Induction of mania by L-dopa in a nonbipolar patient. Journal of Clinical Psychopharmacology, 5, 338-339.

[89] Ryback, R.S. and Schwab, R.S. (1971) Manic response to levodopa therapy. Report of a case. The New England Journal of Medicine, 285, 788-789. doi:10.1056/NEJM197109302851409

[90] Tune, L.E., Folstein, M., Rabins, P., Jayaram, G. and McHugh, P. (1982) Familial manic-depressive illness and familial Parkinson's disease: A case report. Johns Hopkins Medical Journal, 151, 65-70.

[91] Heberlein, I., Ludin, H.P., Scholz, J. and Vieregge, P. (1998) Personality, depression, and premorbid lifestyle in twin pairs discordant for Parkinson's disease. Journal of Neurology, Neurosurgery \& Psychiatry, 64, 262-266. doi:10.1136/jnnp.64.2.262

[92] Bhatia, K.P., Daniel, S.E. and Marsden, C.D. (1993) Familial parkinsonism with depression: A clinicopathological study. Annals of Neurology, 34, 842-847. doi:10.1002/ana.410340614

[93] Aarsland, D., Ballard, C., Larsen, J.P. and McKeith, I. (2001) A comparative study of psychiatric symptoms in dementia with Lewy bodies and Parkinson's disease with and without dementia. International Journal of Geriatric Psychiatry, 16, 528-536. doi:10.1002/gps.389

[94] Arabia, G., Grossardt, B.R., Geda, Y.E., Carlin, J.M., Bower, J.H., Ahlskog, J.E., Maraganore, D.M. and Rocca, W.A. (2007) Increased risk of depressive and anxiety disorders in relatives of patients with Parkinson disease. Archives of General Psychiatry, 64, 1385-1392. doi:10.1001/archpsyc.64.12.1385 
[95] Berkson, J. (1946) Limitations of theapplication of fourfold table analysis to hospital data. Biometrics Bulletin, 2, 47-53. doi: $10.2307 / 3002000$

[96] Andersen, B. (1969) Berkson's fallacy. Nordisk Medicin, 81, 729-730.

[97] Hofman, A., Grobbee, D.E., De Jong, P.T. and Van Den Ouweland, F.A. (1991) Determinants of disease and disability in the elderly: The Rotterdam elderly study. European Journal Epidemiology, 7, 403-422. doi:10.1007/BF00145007

[98] Factor, S.A., Molho, E.S. and Brown, D.L. (1995) Combined clozapine and electroconvulsive therapy for the treatment of drug-induced psychosis in Parkinson's disease. The Journal of Neuropsychiatry and Clinical Neuroscience, 7, 304-307.

[99] Wittchen, H.U. (2000) Epidemiological research in mental disorders: Lessons for the next decade of researchThe NAPE Lecture 1999. Nordic Association for Psychiatric Epidemiology. Acta Psychiatrica Scandinavica, 101, 2-10. doi:10.1034/j.1600-0447.2000.101001002.x

[100] Merikangas, K.R. (1990) Comorbidity for anxiety and depression: Review of family and genetic studies. In: Maser, J.D. and Cloninger, C.R., Eds., Comorbidity of Mood and Anxiety Disorders, American Psychiatric Press, Washington DC, 331-348.

[101] Zahner, G.E.P., Hsieh, C.C. and Fleming, J.A. (1995) Introduction to epidemiologic research methods. In: Tsuang, M.T., Tohen, M. and Zahner, G.E.P., Eds., Textbook in Psychiatric Epidemiology, John Willey \& Sons, New York, 23-54.

[102] Peyser, C.E. and Folstein, S.E. (1990) Huntington's disease as a model for mood disorders. Clues from neuropathology and neurochemistry. Molecular and Chemical Neuropathology, 12, 99-119. doi:10.1007/BF03160062

[103] Winokur, G. (1997) All roads lead to depression: Clinically homogeneous, etiologically heterogeneous. Journal Affective Disorders, 45, 97-108. doi:10.1016/S0165-0327(97)00063-3

[104] Baxter, L.R., Jr., Schwartz, J.M., Phelps, M.E., Mazziotta, J.C., Guze, B.H., Selin, C.E., Gerner, R.H. and Sumida, R.M. (1989) Reduction of prefrontal cortex glucose metabolism common to three types of depression. Archives of General Psychiatry, 46, 243-250. doi:10.1001/archpsyc.1989.01810030049007

[105] Biver, F., Goldman, S., Delvenne, V., Luxen, A., De, M.V., Hubain, P., Mendlewicz, J. and Lotstra, F. (1994) Frontal and parietal metabolic disturbances in unipolar depression. Biological Psychiatry, 36, 381-388. doi:10.1016/0006-3223(94)91213-0

[106] Charlton, C.G. (1997) Depletion of nigrostriatal and forebrain tyrosine hydroxylase by S-adenosylmethionine: A model that may explain the occurrence of depression in Parkinson's disease. Life Science, 61, 495-502. doi:10.1016/S0024-3205(97)00409-8

[107] Mayeux, R. (1990) The “serotonin hypothesis” for depression in Parkinson's disease. Advance Neurology, 53, 163-166.

[108] Angst, J. and Merikangas, K.R. (1997) The depressive spectrum: Diagnostic classification and course. Journal of Affective Disorders, 45, 31-40. doi:10.1016/S0165-0327(97)00057-8

[109] Winokur, G., Coryell, W., Keller, M., Endicott, J. and Leon, A. (1995) A family study of manic-depressive (bipolar I) disease. Is it a distinct illness separable from primary unipolar depression? Archives of General Psychiatry, 52, 367-373. doi:10.1001/archpsyc.1995.03950170041006

[110] Stahl, S.M. (1988) Basal ganglia neuropharma-cology and obsessive-compulsive disorder: The obsessive-compulsive disorder hypothesis of basal ganglia dysfunction. Psychopharmacology Bulletin, 24, 370-374.

[111] Alexander, G.E., Crutcher, M.D. and DeLong, M.R. (1990) Basal ganglia-thalamocortical circuits: Parallel substrates for motor, oculomotor, "prefrontal" and "limbic" functions. Progress in Brain Research, 85, 119-146. doi:10.1016/S0079-6123(08)62678-3

[112] Austin, M.P. and Mitchell, P. (1995) The anatomy of melancholia: Does frontal-subcortical pathophysiology underpin its psychomotor and cognitive manifestations? Psychological Medicine, 25, 665-672. doi:10.1017/S0033291700034929

[113] Mayberg, H.S. (1997) Limbic-cortical dysregulation: A proposed model of depression. The Journal of Neuropsychiatry and Clinical Neuroscience, 9, 471-481.

[114] Duman, R.S., Heninger, G.R. and Nestler, E.J. (1997) A molecular and cellular theory of depression. Archives of General Psychiatry, 54, 597-606. doi:10.1001/archpsyc.1997.01830190015002

[115] Post, R.M. (1997) Molecular biology of behavior. Targets for therapeutics. Archives of General Psychiatry, 54, $607-$ 608. doi:10.1001/archpsyc.1997.01830190025003

[116] Kennedy, S.H., Javanmard, M. and Vaccarino, F.J. (1997) A review of functional neuroimaging in mood disorders: Positron emission tomography and depression. Canadian Journal of Psychiatry, 42, 467-475.

[117] Cummings, J.L. (1993) Frontal-subcortical circuits and human behavior. Archives of Neurology, 50, 873-880. doi:10.1001/archneur.1993.00540080076020

[118] Mayberg, H.S., Starkstein, S.E., Sadzot, B., Preziosi, T., Andrezejewski, P.L., Dannals, R.F., et al. (1990) Selective hypometabolism in the inferior frontal lobe in depressed patients with Parkinson's disease. Annals Neurology, 28, 57-64. doi:10.1002/ana.410280111

[119] Mayberg, H.S. (1994) Frontal lobe dysfunction in secondary depression. Journal of Neuropsychiatry and Clinical Neuroscience, 6, 428-442.

[120] Majoor-Krakauer, D., Ottman, R., Johnson, W.G. and Rowland, L.P. (1994) Familial aggregation of amyotrophic lateral sclerosis, dementia, and Parkinson's disease: Evidence of shared genetic susceptibility. Neurology, 44, 1872-1877.

[121] Robinson, R.G., Chemerinski, E. and Jorge, R. (1999) Pathophysiology of secondary depressions in the elderly. Journal of Geriatric Psychiatry and Neurology, 12, 128136. doi:10.1177/089198879901200306

[122] Postuma, R.B., Gagnon, J.F. and Montplaisir, J. (2010) 
Clinical prediction of Parkinson's disease: Planning for the age of neuroprotection. Journal of Neurology, Neurosurgery \& Psychiatry, 81, 1008-1013. doi:10.1136/jnnp.2009.174748

[123] Bech, P. (1993) Rating scales for psychopatology, health status and quality of life. Springer-Verlag, Berlin Heidelberg, New York.

[124] Leentjens, A.F., Verhey, F.R., Lousberg, R., Spitsbergen, H. and Wilmink, F.W. (2000) The validity of the Hamilton and Montgomery-Asberg depression rating scales as screening and diagnostic tools for depression in Parkinson's disease. International Journal of Geriatric Psychiatry, 15, 644-649.

doi:10.1002/1099-1166(200007)15:7<644::AID-GPS167 $>3.0 . \mathrm{CO} ; 2-\mathrm{L}$

[125] Keitner, G.I., Ryan, C.E., Miller, I.W., Kohn, R. and Epstein, N.B. (1991) 12-month outcome of patients with major depression and comorbid psychiatric or medical illness (compound depression). American Journal of Psychiatry, 148, 345-350.

[126] Aarsland, D., Andersen, K., Larsen, J.P., Lolk, A., Nielsen, H. and Kragh-Sorensen, P. (2001) Risk of dementia in Parkinson's disease: A community-based, prospective study. Neurology, 56, 730-736.

[127] Brandt-Christensen, M., Kvist, K., Nilsson, F.M., Andersen, P.K. and Kessing, L.V. (2006) Treatment with antidepressants and lithium is associated with increased risk of treatment with antiparkinson drugs: A pharmacoepidemiological study. Journal of Neurology, Neurosurgery \& Psychiatry, 77, 781-783. doi:10.1136/jnnp.2005.083345

[128] Brandt-Christensen, M., Kvist, K., Nilsson, F.M., Andersen, P.K. and Kessing, L.V. (2007) Treatment with antiparkinson and antidepressant drugs: A register-based, pharmaco-epidemio-logical study. Movement Disorders, 22, 2037-2042. doi:10.1002/mds.21472 